\title{
INFIDELIDADES VELADAS: ULISSES ENTRE CIRCE E CALIPSO NA ODISSEIA
}

\author{
Teodoro Rennó Assunção* \\ Universidade Federal de Minas Gerais
}

RÉSUMÉ: Cet article veut commenter ponctuellement les rapports sexuels d'Ulysse avec les déesses-nymphes Circé et Calypso dans l'Odyssée, en essayant de discuter, dans le cadre majeur de son mariage avec Pénélope, la pertinence d'une perception de ces deux rapports hors mariage comme des "infidélités". L'ordre de présentation de ces deux épisodes suit l'ordre chronologique interne de l'histoire et non pas celui du récit direct de l'Odyssée, en raison de la priorité de Circé comme modèle caractériel et narratif. Le commentaire essaie d'être bien attentif à la manière (quelquefois elliptique) de présentation de ces rapports sexuels, en dégageant les hypothèses d'interprétation possibles, et ensuite, dans une brève conclusion, il essaie de les caractériser et penser dans l'ensemble du poème.

MOTS-CLÉS: infidélités; Ulysse; Circé; Calypso; Odyssée.

objetivo primeiro deste artigo é comentar pontualmente as relações sexuais de Ulisses com as deusas-ninfas Circe e Calipso na Odisseia, tentando discutir, no quadro maior de seu casamento com Penélope, a pertinência de uma percepção destas duas relações extraconjugais como "infidelidades". ${ }^{1}$ Dada a básica limitação deste escopo,

\footnotetext{
^teorenno@gmail.com

${ }^{1}$ Este termo, que pode despertar a curiosidade do leitor moderno, não serve como tradução, nem mesmo aproximada, para nenhum termo grego presente no texto original, o que não impede, porém, que ele possa eventualmente designar um tema ou questão apreensível apenas a partir das situações narrativas deste mesmo texto (desafiando, assim, uma abordagem lexical estrita para a qual um tema ou questão só pode existir se existir uma palavra que o designe).
} 
evitaremos comentar uma série de elementos importantes para uma compreensão mais precisa dos conjuntos narrativos que compõem estes dois episódios (em sua inserção e conexão interna no conjunto das "viagens maravilhosas" de Ulisses, cantos IX a XII, e na totalidade narrativa do poema), não deixando, no entanto, de estar pressuposta ou implícita neste comentário uma certa interpretação de conjunto da Odisseia.

Seria preciso dizer que uma primeira aproximação entre estas duas deusas-ninfas se justifica não apenas por similaridades em sua natureza ou modo de ser (ambas, por exemplo, são descritas como

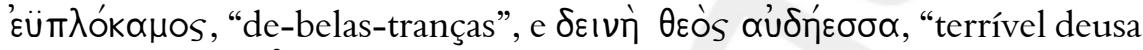
de voz humana", assim como ambas são cantoras enquanto tecem), mas também por similaridades nos episódios que narram as suas relações com Ulisses (ambas habitam ilhas, hospedam Ulisses durante muito tempo, têm relações sexuais com ele, fazem juramentos de não prejudicá-lo, oferecem instruções, provisões e um vento favorável para sua partida, sendo que nos dois episódios o deus Hermes aparece para salvar Ulisses). ${ }^{3}$

Estas similaridades constituem, porém, apenas um fundo contra o qual se destacam diferenças fundamentais (que incluem ou incidem sobre o ponto que é nosso tema): por exemplo, Calipso hospeda Ulisses por um período de tempo (sete anos) bem maior do que Circe (um ano); o modo ou frequência das relações sexuais e afetivas das duas com Ulisses é também diferenciado (Calipso sendo mais íntima e apaixonada do que Circe); o juramento feito por Circe é uma necessidade para a proteção de Ulisses (segundo o conselho de Hermes), enquanto o juramento feito por Calipso atende a um medo de Ulisses que não corresponde a uma necessidade objetiva; as instruções de Circe são muito mais precisas e completas do que as de Calipso; e o deus Hermes, no episódio de Circe, aparece diretamente a Ulisses, fornecendo-lhe o antídoto contra a perigosa droga da deusa, enquanto, no episódio de Calipso, ele apenas transmite à deusa as ordens de Zeus.

Se, por sua aparição anterior na ordem direta da narrativa e por seu caráter psicológico mais reconhecivelmente antropomorfo, Calipso

\footnotetext{
${ }^{2}$ Cf. Nagler, M. N. Dread Goddess revisited. In: Shein, S. (org.). Reading the "Odyssey". Selected interpretive essays. Princeton: University Press, 1996, p. 142: In other words, 'speaking' is normally an attribute of humans; the phrase "theos audeēssa" means (...) a divinity who had taken on (...) the ability to speak to humans.

${ }^{3}$ Cf. Louden, B. The "Odyssey". Structure, narration, and meaning. Baltimore: The Johns Hopkins University Press, 1999, p. 105: Both island-dwelling, chthonic goddesses entertain Odysseus for lengthy periods of time, have sex with him, swear oaths not to harm him, and offer advice, provisions, and a wind on his departure. In both episodes, Hermes intervenes for Odysseus' sake.
} 
pode parecer constituir o modelo a partir do qual (e por subtração ou empobrecimento) é construída a personagem "mais primitiva" de Circe, as comparações sumárias que acabamos de fazer entre as duas sugeririam antes uma espécie de desvio (ou caráter secundário) narrativo do episódio de Calipso e não do de Circe. No longo e seminal ensaio "Die Abenteuer der Odyssee" (ou, na tradução para o inglês usada aqui, "The Adventures in the Odyssey"), ${ }^{4}$ Karl Reinhardt, ao comparar os dois juramentos das deusas pedidos por Ulisses (segundo uma mesma fórmula: Od. V, 178$179=$ Od. X, 343-344), reconhece que, no caso de Circe, Ulisses teme a perda (na cama de Circe) de sua virilidade, o que faz do seu pedido uma demonstração de prudência e inteligência prática, enquanto no caso de Calipso o que ele teme é algo de indeterminado e ameaçador no futuro, o que faz de seu pedido e expectativa em relação a Calipso uma espécie de erro (que curiosamente, no entanto, criará uma ocasião para uma delicada manifestação de carinho de Calipso). K. Reinhardt conclui, portanto, considerando que - dada a razão bem fundada do medo de Ulisses em relação a Circe e a ausência de razão objetiva para o medo deste em relação a Calipso (só possível após a assembleia dos deuses que decide seu retorno) - o medo em relação a Calipso não pode ser anterior ao medo em relação a Circe. ${ }^{5}$ Semelhantemente, no caso de Circe cantando enquanto tece (atividade doméstica caracteristicamente feminina, acrescentaríamos), o canto é um elemento de sedução necessário à captura dos companheiros de Ulisses, mas, no caso de Calipso, dada a ausência de um auditor possível (Ulisses estando junto ao mar), ele é esvaziado de uma função narrativa específica. ${ }^{6}$

${ }^{4}$ Cf. Reinhardt, K. The adventures in the "Odyssey". In: Shein, S. (org.). Reading the "Odyssey”. Selected interpretive essays. Princeton: University Press, 1996, p. 63-132. Apenas para cotejamento, cf. Reinhardt, K. Die Abenteuer der Odyssee. In: und Geist. Göttingen: Vandenhoeck \& Ruprecht, 1960, p. 47-124. . Tradition

${ }^{5}$ Cf. Reinhardt, op. cit., p. 97-98: The first time he fears the loss of his manly strength - there is reason enough for such a fear if one shares the bed of Circe - the second time he fears something that cannot be described, something threatening in a dark future. Yet when he asks for his oath from Circe, he proves to be foresighted and clever, a master of the situation, the hero of the adventure; but in the other case, when making the same demand, he makes a mistake. (...) Which is earlier and which later here? Odysseus as the one who is groundlessly afraid or as the man who is cautious with a reason? There is no possibility of a doubt. Odysseus can only fear needlessly after the gods want his return, after the council of the gods with which the Odyssey begins. (...) The latter cannot be older than the former. ${ }^{6} \mathrm{C}$. Reinhardt, op. cit., p. 96: Both sing with beautiful voices as they go up and down at the loom. The same line is in both places. Circe's song cannot be cut from the story in that it is a necessary part of the adventure. (...) Yet we ask: for whom does Kalypso sing? Does she also sing so that a surprised stranger may want to come in, so that he will call to her and she can open the door and invite 
Já Bruce Louden, em The "Odyssey": structure, narration, and meaning ao propor um padrão narrativo de encontros de Ulisses com tipos femininos poderosos que incluiriam Arete e Penélope, além de Circe [padrão que poderia ser resumido assim: "Ulisses chega a uma ilha, não sabendo onde está. Um ajudante divino aparece, aconselhando-o sobre como abordar uma poderosa figura feminina que controla o acesso à próxima fase de seu retorno ao lar e chamando a atenção para possíveis dificuldades em relação a um bando de homens jovens. (...) Ela lhe impõe um teste, depois do que Ulisses, tendo passado com sucesso pelo teste, ganha sua simpatia e ajuda, obtendo acesso à nova fase de seu retorno ao lar.” $]^{7}$ - chega à conclusão de que Calipso é uma espécie de exceção ou anti-tipo em relação às outras figuras femininas poderosas, mas que, sendo ela a primeira na ordem narrativa direta e tendo muitas similaridades genéricas com Circe, nós (os receptores) somos enganados pela construção do poema, não percebendo o quanto ela é diferente e excepcional. Enquanto um desvio consistente em relação às outras fêmeas poderosas, ela deve ser, pois, uma variação construída pelo compositor contra um padrão dominante, sendo ela (neste sentido) "posterior".

Este breve resumo dos argumentos e posições (que nos parecem basicamente corretos) de Karl Reinhardt e Bruce Louden quanto à

him? Odysseus is sitting far away by the sea. Is she singing for Hermes, whom she is not expecting? Or is she singing for herself? She must be.

${ }^{7}$ Este resumo essencial e esquemático do padrão narrativo proposto por Bruce Louden foi feito a partir de recortes (traduzidos aqui por mim) da sua primeira apresentação logo na segunda página do primeiro capítulo do livro (cf. Louden, op. cit., p. 2), apresentação esta que preferimos não retomar aqui. No capítulo sobre Calipso ele retoma, de um outro e instrutivo modo, este padrão: Unlike the trio of Kirke, Arete, and Penelope, Kalypso is not a figure who is initially suspicious, distant, or even hostile toward him. (...) Consequently, all but one of the other motifs in the narrative pattern relating to the powerful females are either missing or inverted in Kalypso's case: she imposes a test on him, whereupon Odysseus, having successfully passed the test, wins her sympathy and help, obtaining access to the next phase of his homecoming. Their understanding is made manifest in her hospitable offer of a bath. Furthermore, Odysseus is now offered sexual union and/or marriage with the female (p. 108-109).

${ }^{8}$ Cf. Louden, op. cit., p. 122: From a number of perspectives Kalypso is the more distinctive figure, an antitype to the other females Odysseus encounters on his voyage home. But because the audience encounters Kalypso first, sequentially, and because she shares considerable generic similarities with Kirke, we have greater difficulty in perceiving how different she is, and perhaps tend to see her as more like Kirke than she really is. The poem seems fashioned with an eye to deceiving us as to how different the Ogygian goddess is. As she departs so consistently from the other powerful females, she is a variation manipulated by the composer against a dominant pattern. In this sense she is "later". 
anterioridade de Circe deve, pois, justificar a ordem de exposição que adotaremos, ordem que coincide com a ordem cronológica interna da estória, mas não com a ordem direta da narrativa (o que, sem dúvida, não é uma sutileza menor do compositor da Odisseia).

\section{Circe}

Se tentarmos pensar o conjunto do episódio de Circe, tal como contado por Ulisses, poderemos nos surpreender com a parcimônia de dados sobre a relação erótica entre a deusa ou ninfa (com forma de mulher) e o herói da guerra de Troia. ${ }^{9}$ Ulisses, informado por Euríloco da transformação mágica (efetivada por Circe) de vinte de seus companheiros em porcos, parece bem mais preocupado em salvá-los, quando se decide a ir ao encontro de Circe, do que em desfrutar eventualmente do amor da deusa, que neste primeiro momento assume antes a figura de uma maligna feiticeira. E é não apenas o $\mu \omega \hat{\lambda} u$ (planta mágica, fornecida por

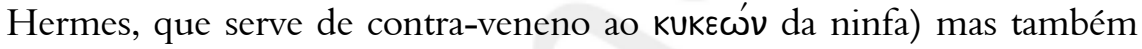
uma instrução do deus o que, no relato de Ulisses, justifica que ele aceite partilhar o leito da ninfa (mas apenas após ela ter jurado que não o tornaria covarde e não-viril, ainda segundo uma orientação de Hermes):

quando Circe tentar conduzir-te com a sua vara comprida, desembainha a espada de junto da tua coxa e lança-te contra Circe, como se a quisesses matar.

Ela ficará cheia de medo e oferecer-te-á a sua cama.

Pela tua parte, não recuses a cama da deusa, para que ela te solte os companheiros e trate bem de ti.

(Od. X, 293-298, trad. F. L.) ${ }^{10}$

\footnotetext{
${ }^{9}$ Ver, por exemplo, a sóbria advertência de Karl Reinhardt ao comentar a posição de filólogos como Wilamowitz e Eduard Schwartz: In making a charge of base sensuality, they clearly overlook the rhythm of the story. They overlook how little, in comparison with fairy tales, pleasure in love is picked out as the goal of the adventure. The story almost passes over it. First it stops, and only comes to its climax and changes its situation after they enjoy the pleasures of love (op. cit., p. 90).

${ }^{10} \mathrm{O}$ texto grego adotado (e facilmente verificável, poupando-me de citá-lo aqui) é o editado por Thomas W. Allen para a coleção da editora de Oxford [Allen, T. W. (ed.). Homeri Opera tomi III et IV. Oxford: University Press, 1987], tendo sido usado para cotejamento o texto grego editado por Peter von der Mühll [Von der Mühll, P. (ed.). Homeri Odyssea. Leipzig: Teubner, 1993, ed. stereotypa ed. 3. 1962], e a tradução adotada é a de Frederico Lourenço (Homero. Odisseia. Lisboa: Cotovia, 2003), designado pelas iniciais F. L., a não ser quando julguei necessário fazer alguma modificação, o que é então indicado pela qualificação "modificada". Os itálicos,
} 
Sua reação, após ele a ter chamado e ela o ter convidado a entrar, esclarece bem o seu estado anímico então:

Ali de pé, chamei por ela; e a deusa ouviu a minha voz.

Ela saiu logo, abrindo as portas resplandecentes, e convidou-me a entrar; acompanhei-a, afligido no coração. ${ }^{11}$

(Od.X, 311-313, trad. F. L. modificada)

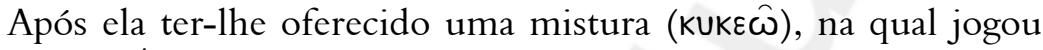
uma droga ( $\phi \alpha ́ \rho \mu \alpha \kappa o v)$, que não o enfeitiçou (assim como é sem efeito contra ele o toque de sua varinha mágica), Ulisses segue a ordem do deus e desembainha a espada, lançando-se contra ela, como se a quisesse matar, ato que opera nela a transformação radical de feiticeira maligna em protetora e benfazeja fada: ${ }^{12}$

Ela, com um grito, desviou-se e abraçou-me os joelhos;

lamentando-se, dirigiu-me palavras apetrechadas de asas:

(Od. X, 323-324, trad. F. L.)

Nesta fala, após tê-lo reconhecido (também segundo uma profecia de Hermes) pela potência de seu vóos ("percepção da situação"), ela irá, como se agora enfeitiçada por ele (mas livre, enfim, de um confronto futuro anunciado e agora já cumprido), lhe propor imediatamente que se deitem juntos (restando, porém, neste primeiro momento, uma dúvida possível quanto às reais intenções dela, donde a precaução do juramento):

que visam apenas a destacar as partes do texto citado focadas pelo comentário, são sempre de minha autoria. As traduções para o português de trechos de comentadores em inglês ou francês citados no corpo do texto do artigo são minhas também.

${ }^{11}$ A ocorrência do verso 312 e do primeiro pé (um dáctilo) do verso 313 no episódio do enfeitiçamento dos companheiros de Ulisses (verso 230 e primeiro pé do verso 231) serve para marcar melhor a diferença entre a atitude ingênua destes e a advertida sobriedade de Ulisses, tal como bem o indicou Charles Segal (Segal, C. Circean Temptations: Homer, Vergil, Ovid. Transactions of the American Philological Association. Baltimore, vol.XCIX, p. 419-442, p. 427, 1968):

Ela saiu logo, abrindo as portas resplandecentes, e convidou-os a entrar; e eles, inscientes, entraram todos.

(Od. X, 230-231, trad. F. L.)

${ }^{12}$ Esta fórmula, que parece descrever bem a dualidade (e transformação) da natureza de Circe, é uma retomada da fórmula de Gabriel Germain resumindo o movimento básico do episódio a partir das duas posições antitéticas de Circe: Elle commence en enchanteresse perfide et finit en bonne fée (Germain, G. Genèse de l'Odyssée. Paris: Presses Universitaires de France, 1954, p. 249). 
Mas repõe a espada na bainha, pois subiremos agora na nossa cama, para que nós dois, nos misturando na cama e com amor, confiemos um no outro.

(Od.X, 333-335, trad. F. L. modificada)

Se, como sugere Charles Segal em "Circean Temptations: Homer, Vergil, Ovid", a espada poderia (também neste contexto) funcionar como signo da sexualidade masculina de Ulisses, ${ }^{13}$ ela é - segundo indica a retomada (por Od. X, 321) do verso 190 do canto I da Ilíada, que descreve Aquiles desembainhando a espada para matar Agamêmnon - primeiramente uma marca da sua identidade de guerreiro vindo de Troia (ver, por exemplo, a insistência de Ulisses em conservar, por meio do armamento, sua identidade guerreira, mesmo na inútil luta contra o monstro Cila), como se, mesmo no teste sexual decisivo deste pequeno "conto de fadas" (em que a contra-droga de Hermes é, portanto, necessária), o herói (cuja natureza não pertence a este mundo maravilhoso) precisasse manter algo do código guerreiro homérico.

Ulisses, no entanto, após descrever a sua exigência de um juramento de Circe (de que não o tornaria, uma vez desarmado, covarde e não-viril) e o cumprimento deste pela deusa, descreve discreta e economicamente - sem nenhuma alusão à mistura carnal ou ao amor

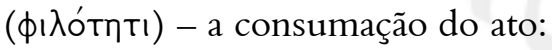

E depois que jurou e pôs termo ao juramento, foi então que subi para a cama lindíssima de Circe. ${ }^{14}$

(Od.X, 346-347, trad. F. L.)

Mesmo que não haja uma explicitação do ato na oração destacada

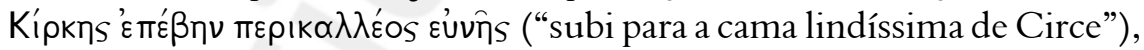

\footnotetext{
${ }^{13}$ Cf. Segal, op. cit., p. 425-426: This sword also matches her sexual seduction, for it is not only a mark of his heroic identity (10.321, for instance, uses the formula describing Achilles when he draws against Agamemnon, Iliad 1.190); it is also a symbol of his male sexuality.

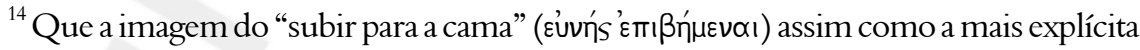
do "misturar-se" ( $\mu$ ıүívaı) sinalizem discreta e economicamente a consumação do ato sexual em Homero (sem jamais se demorarem em detalhes íntimos eróticos que possam satisfazer a curiosidade de um voyeur) é o que nos lembra a sóbria formulação dojuramento de Agamêmnon de jamais ter tido uma relação sexual com Briseida (relação pensada aí como uma mera ordem ou norma, $\theta^{\prime} \varepsilon \mu$ s, entre homens e mulheres):
}

nunca com ela subi para a cama nem a ela me misturei como é norma entre os humanos, homens e mulheres.

(Il. IX, 133-134, trad. F. L. modificada) 
a oração do verso seguinte ("Entretanto as servas afadigavam-se no palácio”, Od. X, 348) introduz uma simultaneidade que é signo suficiente de que, após ter subido para a cama de Circe, o casal lá fazia ou fez alguma coisa, que não poderia ser outra do que a realização da condição necessária para a liberação de seus companheiros, tal como prevista por Hermes, ou seja: a consumação do ato sexual. ${ }^{15}$

$\mathrm{Na}$ segunda vez em que o ato de subir para a cama de Circe é mencionado (quando Ulisses, depois de um ano inteiro e mais um último dia de recuperação do "ânimo" em banquetes de carne e vinho, após a perda da maior parte dos companheiros nos episódios do Ciclope e dos Lestrigões, enfim é lembrado pelos companheiros restantes de que é hora de retornar à terra pátria), este ato de subir pra cama aparece como uma participial "subindo para a cama lindíssima de Circe" (Кіркпs 'єпıßа́s

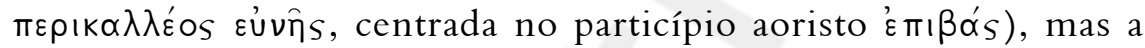
consumação do ato está excluída pela imediata sequência descrita pelo verbo finito da principal ("supliquei-lhe", ' $\left.\varepsilon \lambda \lambda_{I}+\alpha ́ v \varepsilon \cup \sigma \alpha\right)$, súplica cujo conteúdo volta a ser a preocupação pelo retorno e pelos companheiros que choram. Então, em oposição aos companheiros que, com a chegada da noite, se deitaram pelo salão escurecido, Ulisses diz:

Pela minha parte, subindo para a cama lindíssima de Circe, supliquei-lhe pelos joelhos; e a deusa ouviu a minha voz.

(Od.X, 480-482, trad. F. L. modificada)

Ainda que a consumação do ato não seja descrita desta vez, podemos supor que, após um dia de banquete com os companheiros (que não estarão mais presentes, por exemplo, na ilha de Calipso), Ulisses pudesse também - durante todo este aprazível ano de banquetes na

${ }^{15}$ Cf. Heubeck, A. Books IX-XII. In: Heubeck, A.; Hoekstra, A. A Commentary on Homer's "Odyssey" vol. II, Books ix-xvi. Oxford: University Press, 1990, p. 62: As Hermes had foreseen, the release of the companions follows after the consummation of the relationship between Odysseus and Circe and the preparations for a feast. It is, however, odd that concern for the crew should delay their eating together (373), but not their sleeping together (...).William B. Stanford, em seu comentário sobre a Odisseia, nada diz sobre o verso 347 do canto X nem sobre esta ação conjunta de Ulisses e Circe [Stanford, W. B. (ed.). The "Odyssey" of Homer vol. I. New York: Macmillan, 1987, p. 375], assim como também nada os escoliastas da Odisseia reunidos na edição de W. Dindorf [Dindorf, W. (ed.). Scholia greca in Homeri Odysseam tomus II. Oxonii: E Typographeo Academico, 1855, p. 470]. Ameis/ Hentze limitam-se a assinalar a repetição do verso em 480: $347=480$. [Ameis, K. F.; Hentze, C. (eds.). Homers Odyssee, Erster Band. Zweites Heft. Leipzig: Teubner, 1908, p. 123]. 
ilha de Circe - ir se deitar algumas vezes com a deusa-ninfa (ato supostamente habitual descrito pela expressão "subir para a cama de Circe”), mas para conversar e se misturarem em amor. O fato, no entanto, é que isso não é mencionado diretamente por Ulisses nem uma única vez (além da primeira que aparece como necessária à liberação dos companheiros), estando o foco explícito deste narrador - assim como da primeira vez, onde é a recusa do banquete preparado pelas servas de Circe o que permite a ele obter a retransformação de seus companheiros em homens - bem mais no banquete do que propriamente na cama.

Mas uma última ocorrência do deitarem-se juntos Circe e Ulisses - ainda que sem a presença da expressão "subir para a cama de Circe" (pois então eles estão na praia) ou de outra explicitação qualquer do ato sexual - parece, pela privacidade íntima da cena, voltar a sugerir a possibilidade da relação sexual, ou, ao menos, segundo a postura de

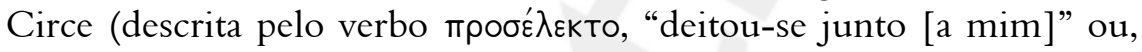
no ajuste de F. Lourenço, "deitando-se ao meu lado"), a existência de uma intimidade entre os dois que sinalizaria um hábito adquirido do qual muito improvavelmente não faria parte a eventual consumação do ato sexual. Após Ulisses e os companheiros restantes voltarem do Hades, Circe, curiosa por notícias, forneceu-lhes provisões para um farto banquete que durou todo um dia, sendo que, com a chegada da noite, os companheiros de Ulisses "deitaram-se junto das amarras da nau” (Od. XII, 32). O narrador Ulisses então continua assim o seu relato:

\section{Mas Circe, levando-me pela mão, sentou-me longe dos queridos companheiros; deitando-se ao meu lado, tudo quis saber; e eu tudo lhe contei, pela ordem certa.}

(Od.XII, 33-35)

A interpretação de Bruce Louden (que admite, porém, a inexistência de provas textuais conclusivas para ela $)^{16}$ de que a única ocasião em que Ulisses e Circe consumaram o ato sexual foi quando do seu primeiro encontro (segundo a ordem de Hermes) é também plausível, mas ela parece desconsiderar que, diferentemente do episódio de Calipso contado pelo narrador da Odisseia, aqui o narrador é Ulisses (que há pouco

\footnotetext{
${ }^{16}$ Cf. Louden, op. cit., p. 111: The text only once mentions Odysseus sleeping with Kirke: And then I mounted the surpassingly beautiful bed of Kirke' (10.347). Commentators tacitly generalize on the basis of this single mention that Odysseus has sex with Kirke regularly during the whole year. (...) Though the text does not offer conclusive evidence one way or the other, the evidence suggests that Odysseus only has sex on the one occasion when Hermes instructs him to do so.
} 
recusou a oferta da mão de Nausícaa, movido pelo desejo do retorno) e a audiência, a corte do rei feácio Alcínoo, onde (segundo Atena) a presença da rainha Arete é decisiva para sua boa chance de rever a pátria e a esposa. Ele poderia, portanto, muito bem ter tido algum pudor e prudência em não narrar para uma mulher e rainha (assim como não o fará depois para Penélope) as eventuais várias noites de prazer amoroso com uma deusaninfa (noites que, segundo o seu relato, não teriam deixado em nenhum dos dois marca alguma de paixão), como se ele tivesse interesse em deixar no auditório, neste momento em que ele depende de Arete e de Alcínoo para ser reconduzido à Ítaca, uma impressão impecavelmente sóbria de si mesmo. ${ }^{17} \mathrm{Na}$ inexistência, porém, de provas textuais definitivas, não é preciso escolher entre uma ou outra posição, pois o compositor do poema poderia, deixando este relato para o Ulisses-narrador diante da audiência dos Feácios, estar sugerindo não só o interesse deste em não narrar tudo explicitamente, mas também a impossibilidade de verificar ou demonstrar o que quer que seja sobre eventuais relações sexuais (extra-conjugais) de um narrador que não quer se revelar inteiramente. Neste sentido, a discrição do personagem-narrador Ulisses - que mobiliza também a curiosidade do auditor (ou leitor) da Odisseia - poderia também ser transferida (em uma homologia bem odisseica) ao compositor do poema.

Mas, se admitíssemos a também plausível hipótese de que Ulisses e Circe mantiveram relações sexuais durante este ano de banquetes contínuos em sua ilha (conjunto de prazeres que, mais encantatório do que a droga funesta de Circe, poderia muito bem justificar o seu total esquecimento do retorno, a ponto de necessitar ser lembrado deste por seus companheiros), ${ }^{18}$ poderia estranhar a um leitor formado no

\footnotetext{
${ }^{17}$ Ver para uma percepção da possível astúcia de Ulisses, neste caso, para com o auditório, o comentário de Édouard Delebecque no subcapítulo "Ulysse et Circé" de Construction de l'“Odyssée”" (cf. Delebecque, E. Construction de l'“Odyssée”. Paris: Les Belles Lettres, 1980, p. 110-113).

${ }^{18}$ Diferentemente do que ocorre quando da transformação dos companheiros de

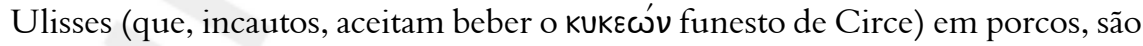
eles quem, uma vez retransformados em homens, advertem um Ulisses esquecido do retorno e como subjugado pelos prazeres do banquete (e eventualmente do sexo). A imagem algo estoica de uma baixa e animalesca sensualidade tanto de Circe quanto dos companheiros de Ulisses só é possível a partir de uma leitura alegórica

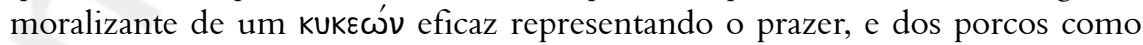
representação dos torpes instintos carnais, tal como a encontraremos em Horácio: Sirenum uoces et Circce pocula nosti;/ Que si cum sociis stultus cupidusque bibisset,/ Sub domina meretrice fuisset turpis et excors,/Vixisset canis immundus, uel anima luto sus. (cf. Epistolas, livro
} 
gosto romântico moderno que Circe jamais expresse o desejo de se tornar a esposa de Ulisses ou conservá-lo apenas para si, e nem qualquer sentimento exacerbado de paixão, assim como parece não ter dificuldade alguma de se despedir dele quando a hora é chegada (ao que corresponde obviamente, da parte de Ulisses, um igual distanciamento, mas jamais um qualquer desprezo). Uma tal postura prática e hedonista parece, no entanto, muito mais leve e menos aborrecida (do que a de Calipso) para um Ulisses que, se pode aceitar desfrutar do prazer de um affaire temporário, no fim das contas, jamais abre mão do retorno à sua esposa mortal. ${ }^{19}$

Factualmente e apesar desta demasiado inumana "frieza sentimental" (de uma "belle dame sans merci"), Circe, após o primeiro (ou único) ato sexual com Ulisses - que para ela, portanto, é o teste decisivo - torna-se inteiramente protetora de Ulisses e seus companheiros, não apenas lealmente predizendo a ele e o orientando sobre as provas (ou provações) ainda a enfrentar para tornar possível o seu retorno, mas também materialmente o ajudando tanto quando da viagem ao Hades, com o dom sacrificial necessário de um bode e de uma ovelha negra, quanto da partida final, alimentando e restaurando-os na véspera, após a chegada do Hades, e enviando-lhes então um "vento favorável que enchia a vela" (Od. XII, 149).

A percepção desta diferença, quase sempre a partir de uma comparação com a mais marcadamente antropomorfa Calipso, em vez de levar a uma apressada consideração negativa de Circe como personagem tosca ou primitiva (ou ainda maquinal), ${ }^{20}$ poderia bem mais prudentemente levar à admissão de que - como sugere com argúcia Karl Reinhardt - se trata apenas de um outro modelo de comportamento,

I, II, 23-26; Horace. Euvres complètes II. Satires; Épitres; Art Poétique. Trad. F. Richard. Paris: Garnier, 1950, p. 160). Ver também Buffière, F. 3ème partie, chap. VIII, V. Les luttes du sage contre le plaisir et les vices. In: grecque. Paris: Les Belles Lettres, 1956, p. 377-380.

${ }^{19}$ Cf. Segal, op. cit., p. 424: Circe, in fact, seems to understand her man better than did Calypso. Rather than keep him, a pining unwilling lover, in her bed for seven years, she sends him off at the first signs of uneasiness. Or is her understanding only the keen, practical intelligence of a consistent and determined hedonist, quick to scent the end of a pleasurable affair?

${ }^{20}$ Ver, por exemplo, a descrição final do comportamento de Circe por William B. Stanford: (...) the abruptness of her actions are more those of a marionette than of a fully developed character. But, taken in its general context, her conduct has a sinister automaton-like effect, quite unlike Calypso's manner. She never entirely steps out of that world offairytale which in such an alarming way anticipates the robot-like figures of modern scientific fiction (Stanford, W. B. The Ulysses theme. A study in the adaptability of a traditional hero. Dallas: Spring Publications, 1992, p. 48). 
próprio de personagens de contos de fada ${ }^{21}$ e adequado a uma espécie de feiticeira oriental (como bem indica a localização da ilha de Eeia na abertura do canto XII) ${ }^{22}$ que conhece drogas perigosas e eventualmente fatais, mas que pode também ser uma generosa e delicada anfitriã, bem atenta às necessidades de restauração do corpo e do ânimo humanos por meio de banhos e banquetes (e eventualmente sexo).

\section{Calipso}

Diferentemente de Circe, Calipso - também uma bela deusa-ninfa - acolhe bem Ulisses (que, no entanto, já está só, pois todos os companheiros da última nau restante pereceram), mas dificulta, por interessada omissão, sua partida em direção à Ítaca, ou seja: seu retorno (que ainda deve passar por um último ponto de transição: os Feácios). $\mathrm{O}$ deus Hermes - que, no caso de Circe, propicia com seu antídoto (o $\mu \hat{\omega} \lambda u)$ e com suas instruções (para o ato sexual) a conversão da "feiticeira nefasta" em "fada protetora" - é, no caso de Calipso, quem leva a ordem de Zeus de que ela se despeça rapidamente de Ulisses e permita o seu retorno. Logo que o deus mensageiro (após a contemplação de uma paisagem idílica) entra na gruta de Calipso e a encontra, o narrador da Odisseia diz:

Porém Hermes não encontrou na gruta o magnânimo Ulisses:
na praia estava ele sentado, a chorar no sítio de costume,
torturando o coração com lágrimas, tristezas e lamentos.
E com os olhos cheios de lágrimas fitava o mar nunca vindimado.

(Od. V, 81-84, trad. F. L.)

O auditor (ou leitor) pode então se lembrar da primeira menção à deusa Calipso (que não possui meios mágicos, mas apenas palavras para enfeitiçá-lo), quando Atena, na primeira assembléia dos deuses, no começo do canto I, diz a Zeus, reivindicando o retorno de Ulisses:

${ }^{21}$ Cf. Reinhardt, op. cit., p. 94: Compared with Circe Calypso already shows a very welldeveloped psychology. The fairy tale does not demand this. And yet, if we deny it a psychological element, that does not mean that it misleads us by being unpsychological or psychologically faulty. It only means that one should not measure it in terms of psychology.

${ }^{22}$ Apesar da desorientação de Ulisses quando de sua chegada à ilha de Eeia (cf. Od. X, 190-192), o comecinho do canto XII é suficientemente claro quanto a esta localização: Quando a nau deixou a corrente do rio Oceano,/ chegou às ondas do mar de amplos caminhos/ e à ilha de Eeia, onde da Aurora que cedo desponta/ estão a morada, os lugares das suas danças e o nascer do Sol (Od. XII, 1-4, trad. F. L.). 
Sua [de Atlas] filha retém aquele homem desgraçado, e sempre com palavras suaves e lisonjeiras o encanta, para que Ítaca olvide; mas Ulisses desejoso de no horizonte ver subir o fumo da sua terra tem vontade de morrer - e o teu coração não se comove, Olímpio (...).

(Od. I, 55-60, trad. F. L. modificada)

A expectativa que então pode formar o auditor (ou leitor) quanto à posição de Ulisses face à deusa-ninfa é de algum modo semelhante à noção formada por Arete e Alcínoo, quando ouvem da boca do astucioso Ulisses a seguinte e deliberadamente destorcida versão a respeito de sua relação com Calipso (que o acolheu):

com gentileza me hospedou e alimentou. Prometeu-me a imortalidade, para que eu vivesse sempre isento de velhice.

Mas nunca convenceu o coração dentro do meu peito.

Aí fiquei durante sete anos, e sempre humedecia com lágrimas as vestes imortais que me dera Calipso.

(Od.VII, 256-260, trad. F. L. modificada)

Quando, porém, após transmitida a ordem de Zeus (à qual Calipso cede, apesar de seus protestos), Hermes vai embora de Ogígia e a deusa-ninfa se dirige para junto de Ulisses, o narrador da Odisseia relata (mantendo a primeira expectativa até a cesura do verso 153, para então nos surpreender com uma informação inédita):

Encontrou-o sentado na praia, os olhos nunca enxutos de lágrimas, pois gastava-se-lhe o doce tempo de vida, chorando pelo retorno, já que a ninfa não mais the agradava.

(Od. V, 151-153, trad. F. L. modificada)

É certo que a imediata sequência volta a privilegiar a primeira versão da relação de Ulisses com Calipso, como se (de algum modo) ele jamais a tivesse desejado:

Por obrigação ele dormia de noite ao lado dela nas côncavas grutas, ele não querendo, junto dela que queria."

(Od. V,154-155, trad. F. L. modificada)

Mas a informação inédita revelada pelo primeiro narrador, ainda que de maneira discreta e vaga, não pode mais ser suprimida: "a ninfa

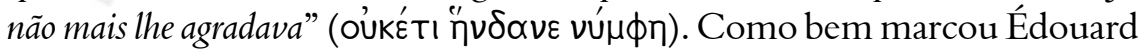


Delebecque, "se ela parou de lhe agradar, é porque ele antes a considerava bem a seu gosto", 23 mesmo que jamais possamos saber com precisão a partir de que momento isso deixou de acontecer.

No entanto, é apenas a própria Calipso quem explicita que a atitude chorosa e nostálgica de Ulisses (em relação à sua terra, como sugeriria a fala já citada de Atena no canto I, cf. Od. I, 57-59, ou, de modo também genérico, em relação ao retorno, cf. Od. V, 151-153) conteria como seu desejo primeiro o de rever a sua esposa, introduzindo, assim, uma segunda mulher (literalmente, pois é uma mortal) e uma relação a três que obstaculiza a relação entre Ulisses e ela, a ninfa, já que a ausente passa a ocupar mais o pensamento de Ulisses do que ela própria, levando-a, em um momento surpreendente de ciúme, a comparar-se com a mortal Penélope (em estatura e beleza), para afirmar sua superioridade como deusa (deixando bem claro, pois, o seu desejo de ser não apenas uma amante provisória mas sim o de ocupar a posição de esposa definitiva):

Mas se soubesses no teu espírito qual é a medida da desgraça que te falta cumprir, antes de chegares à pátria, aqui permanecerias, para comigo guardares esta casa; e serias imortal, apesar do desejo que sentes de ver a esposa por que anseias constantemente todos os dias. Pois eu declaro na verdade não ser inferior a ela,

${ }^{23}$ O conjunto do comentário, após a menção da cena em que Calipso encontra Ulisses chorando na praia, diz: Il pleure évidemment parce que le spectacle de la mer avive en lui le désir de revoir son île natale. Mais Homère ne cache pas la réalité en ajoutant cette précision pleine de sens: Ulysse pleure sur son retour parce que la nymphe ne lui plaît plus. Si elle a cessé de lui plaire, c'est qu'auparavant il la trouvait à son gô̂t (cf. Delebecque, op. cit., p. 105 - o negrito na frase final citada é nosso). Ver também a atenção dada ao decisivo oúḱ'Tı ("não mais") por William S. Anderson: When Homer finally (...) gives us our first picture of the actual Odysseus, he describes the hero weeping and immediately offers therefore two interrelated explanations: Odysseus longs for his home, for the nymph no longer pleases him (5.152-153). That little word oukéti conveys a world of meaning. We see Odysseus at the crucial moment; behind that lie seven years which apparently only gradually produced this decisive state of mind. [Anderson, W. S. Calypso and Elysium. In: Taylor Jr., C. H. (ed.). Essays on the "Odyssey". Bloomington: Indiana University Press, 1963, p. 83]. Ameis/ Hentze, em sua edição da Odisseia, nada dizem

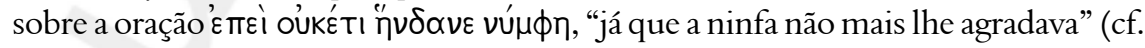
Ameis, K. F.; Hentze, C. Homers Odyssee, Erster Band. Erstes Heft. Leipzig: Teubner, 1920, p. 158). William B. Stanford, em seu comentário sobre a Odisseia, nada diz sobre o verso 153 do canto V (Stanford, op. cit., 1987, p. 298), e nada também J. B. Hainsworth em seu comentário sobre os livros V-VIII da Odisseia (Hainsworth, J. B. Books VVIII. In: Heubeck, A.; West, S.; Hainsworth, J. B. A Commentary on Homer's "Odyssey" vol. I, Books i-viii. Oxford: University Press, 1990, p. 269). 
de corpo ou estatura: não é possível que mulheres compitam em corpo e beleza com deusas imortais.

(Od. V, 206-213, trad. F. L.)

Ulisses, porém, em sua resposta, muito habilmente reconhece a superioridade de Calipso, e não insiste em afirmar o seu amor por uma mulher que (como ele) está envelhecendo e vai morrer um dia (não nos sendo possível, portanto, figurar, a partir do texto da Odisseia, a afirmação do seu cansaço da perfeição da deusa e a sua defesa da temporalidade e precariedade humana de Penélope, como irônica e sagazmente o reformula Eça de Queiróz em "A perfeição" ${ }^{24}$ ). Ele apenas retoma os termos genéricos da volta à casa e do dia do regresso, assim como sua disposição - dada a sua natureza mortal e heróica - para o sofrimento tanto na guerra quanto no mar (cf. Od. X, 221-224):
Deusa sublime, não te encolerizes contra mim. Eu próprio sei bem que, comparada contigo, a sensata Penélope é inferior em beleza e estatura quando se olha para ela. Ela éuma mulher mortal; tu és divina e nunca envelheces. Mas mesmo assim quero e desejo todos os dias voltar a casa e ver finalmente o dia do regresso.

(Od. V, 215-220, trad. F. L.)

A opção de Ulisses pela mortalidade é formulada por ele mesmo, e bem à maneira da Odisseia e de seu protagonista, como uma opção pelo regresso à sua casa e pelos sofrimentos que este pode implicar. Jean-Pierre Vernant, em um comentário conhecido sobre as razões desta recusa por Ulisses da imortalidade que lhe é oferecida por Calipso, ${ }^{25}$ lembra com alguma razão

\footnotetext{
${ }^{24}$ Cf. Queiróz, E. A perfeição. Lisboa: Marginália, 1995, p. 51-53: Tu serás eternamente bela e moça, enquanto os deuses durarem; e ela, em poucos anos, conhecerá a melancolia das rugas, dos cabelos brancos, das dores da decrepitude e dos passos que tremem apoiados a um pau que treme. (...) Mas, ó deusa, justamente pelo que ela tem de incompleto, de frágil, de grosseiro e de mortal, eu a amo e apeteço a sua companhia congênere! (...) Em oito anos, ó deusa, nunca a tua face rebrilhou com uma alegria, nem dos teus verdes olhos rolou uma lágrima, nem bateste o pé com irada impaciência, nem, gemendo com uma dor, te estendeste no leito macio... Eassim trazes inutilizadas todas as virtudes do meu coração, pois que a tua divindade não permite que eu te congratule, te console, te sossegue, ou mesmo te esfregue o corpo dorido com o suco das ervas benéficas.

${ }^{25}$ Cf. Vernant, J.-P. Figures féminines de la mort. In: . L'individu, la mort, l'amour. Paris: Gallimard, 1989, p. 131-152, p. 146-152. A parte sobre Calipso deste ensaio de J.-P. Vernant foi retomada e traduzida para o inglês com o título "The Refusal of Odysseus" na coletânea já citada Reading the "Odyssey” (op. cit., 1996, p. 185-189).
} 
que esta forma de imortalidade (que implicaria para Ulisses permanecer desaparecido do mundo humano) não coincidiria com a única e relativa imortalidade concebível para os mortais em Homero: a imortalidade da glória (dos altos feitos de um herói) na memória das gerações humanas futuras. Mas se o estado de desaparecido impede o cumprimento dos ritos fúnebres (que funcionam como uma primeira memorização daquele que passa então ao estatuto de morto), como bem sugerem as palavras de Telêmaco sobre seu pai citadas por J.-P. Vernant (cf. Od. I, 235-240), ele dificilmente poderia por si mesmo apagar todos os altos feitos de Ulisses na guerra de Troia, já que seus companheiros que sobreviveram, como Nestor e Menelau, podem preservá-los na memória através de seus relatos (assim como o pode o narrador de um poema como a Ilíada). Ou seja: ao menos a memória iliádica de Ulisses poderia assim ainda ser preservada.

O que, no entanto, a opção pela imortalidade oferecida por Calipso representaria para Ulisses seria a impossibilidade de sua glória como o herói do retorno (e dos sofrimentos nele implícitos), isto é: a da sua estória tal como contada pela Odisseia. Pois seriam impossibilitados não só o seu retorno à Ítaca e a difícil retomada do seu lugar (de marido, pai e senhor do palácio) junto aos seus, mas também todas as estórias maravilhosas (e pós-troianas) da viagem de retorno até a chegada à ilha de Calipso, tais como relatadas à corte do rei Alcínoo na Feácia (e resumidas depois para Penélope). Como sugere com argúcia Bruce Louden - retomando o sentido transparente do nome Kalypsô em grego (a partir do verbo kalýptein, "esconder") como "a que esconde" -, "Calipso, cumprindo o prometido por seu nome, não apenas esconde o herói, mas ameaça também esconder a intriga (da Odisseia)". ${ }^{26}$

Mas, segundo William S. Anderson em "Calypso and Elysium", ainda uma outra aproximação seria possível: aquela entre o post-mortem paradisíaco anunciado por Proteu a Menelau (cf. Od. IV, 563-569) e o estado paradisíaco, mas como post-mortem, em que "viveria" (como um morto) Ulisses imortalizado com a imortal Calipso. W. S. Anderson retoma primeiramente as indicações de Hermann Günter que interpreta o nome da ilha de Calipso, Ogygíe, como se referindo ao mundo subterrâneo, onde a água do rio Stýx é também assim designada (cf. Teogonia, v. 806), e propõe que as árvores e as flores que compõem a paisagem idílica em torno da gruta da ninfa,

${ }^{26}$ Cf. Louden, op. cit., p. 106. 
“(...) concebível como uma entrada para o Hades, conotariam a morte. O amieiro negro (kléthre) é provavelmente funéreo; o choupo negro (aígeiros) é descrito por Homero também no Hades, nas clareiras de Perséfone; e o cipreste ainda marca a localização de cemitérios na Itália e Grécia. Os prados floridos, análogos aos campos de asfódelo pelos quais Aquiles anda a passos largos, exibem salsa e íris púrpura, ambas associadas com o ritual fúnebre". ${ }^{27}$

Mas é na definição do que Calipso representa para o próprio Ulisses que W. S. Anderson explicita algo apenas sugerido pelo final da resposta deste para a ninfa: "Em Ogígia, como Menelau o fará algum dia no Elísio, Ulisses escapou de todos os problemas práticos da vida. (...) Tudo o que a vida tinha significado antes disso, a luta constante contra o mar, a astuta persistência em Troia, a dedicação primeira à Ítaca e à sua família, uma atividade incessante com um fim inteligente em vista, tudo isso era inteiramente negado por Calipso. Ela requeria um abandono moral. Sem forçar o termo psicológico, podemos talvez pensar em Ulisses como cedendo temporariamente a seu 'desejo de morte', especialmente depois de todas as provações por que ele passou com seus homens". 28

Se - ainda que não formulada diretamente por Ulisses (ou pelo narrador) - é sedutora e verossímil a hipótese de identificação de um

${ }^{27}$ Cf. Anderson, op. cit., p. 81.

${ }^{28}$ Cf. Anderson, op. cit., p. 85. Uma visão semelhante é proposta por W. B. Stanford em The Ulysses Theme: Homer's account of Ogygia, that flower-strewn, aromatic island, does suggest something of the dolce far niente, in implicit contrast with the rugged, harsh Ithaca which Odysseus so deeply loved. Modern attitudes must not be allowed to cause confusion here. The langorous life of the South Sea Islands has attracted many Europeans in the last century - Gauguin, for example, to Tahiti, Stevenson to Samoa. But such a life of idle hedonism would never satisfy an early Greek, eager for action, society, and renown - least of all a hero so much endowed with practical ability as Odysseus. (...) Calypso's mistake was to think that a man like Odysseus could ever be happy among the violets and the vines of Ogygia (cf. Stanford, op. cit., 1992, p. 50-51).

${ }^{29}$ Apesar de sua aparência psicanalítica, uma tal identificação não é, porém, facilmente localizável no pensamento freudiano a partir de "Além do princípio de prazer", pois o prazer sexual se identificaria, em princípio, com a pulsão de vida e não com a pulsão de morte, como neste caso "paradisíaco" de Ulisses com Calipso (segundo a arguta sugestão de Anderson). No entanto, o grande perigo (para a continuidade da vida) de uma soberania incondicional do princípio de prazer, assim como a necessidade de sua substituição pelo princípio de realidade, são afirmados por Freud em uma passagem de "Além do princípio de prazer" que curiosamente parece evocar a estória do longo retorno de Ulisses: É preciso também lembrar que ante as 
prazer sensorial contínuo (ou não interrompido por sofrimentos) com a morte (pensável como ausência de perturbações), ${ }^{29}$ não o seria tanto a hipótese de uma severa e genérica crítica moral por Ulisses (e, em segundo plano, pelo poeta) ao prazer sensorial e ao dolce far niente. Sabemos que nenhuma crítica ou preocupação deste tipo ocorre ao Ulisses narrador que descreve o ano de banquetes contínuos (e talvez sexo com a ninfa) passado na ilha de Circe, mas ali Ulisses (assim como seus homens) parece reconhecer, tal como sugerida por Circe, a necessidade de um tempo de repouso para restaurar as forças após as últimas e terríveis provações com o Ciclope e os Lestrigões (cf. Od. X, 456-465), mesmo que, ao fim de um ano, ele comece a perigosamente se esquecer do retorno e tenha de ser advertido pelos companheiros para que o faça (cf. Od. X, 372-374). Podemos pensar que semelhantemente, após a perda trágica de todos os seus companheiros restantes (nos episódios de Cila e do rebanho sagrado do Sol), Ulisses pudesse ter sentido a recepção afetuosa (e depois apaixonada) de Calipso como um alívio e um prazer, já que, como sugere o narrador ao dizer "a ninfa não mais lhe

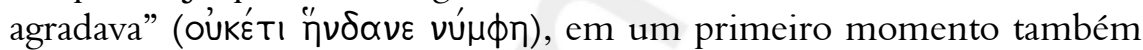
ela lhe teria dado prazer. Mas, como sabemos posteriormente por Ulisses, ele teria passado sete anos isolado com a deusa Calipso (cf. Od. VII, 259), tempo bem maior do que aquele passado com Circe (e, aí, também com os companheiros de sua nau), o que retrospectivamente indica que, após um certo tempo (que o texto não determina ou precisa), Ulisses teria se cansado daquela "vida fácil" e do prazer sexual oferecido por uma ninfa que, diferentemente do distanciamento mais cômodo de Circe, se apaixona por ele e deseja substituir sua esposa mortal. Esta modalização do prazer humano, sugerida não como um princípio moral, mas apenas pelo próprio jogo narrativo das reações de Ulisses, parece assim implicar a inevitável presença do sofrimento e da dor (assim como da atividade, que é retomada por Ulisses precisamente na construção de sua jangada)

dificuldades do mundo exterior, o princípio de prazer desde o início revela-se ineficiente e um perigo para a necessidade de o organismo impor-se ao ambiente. Assim, ao longo do desenvolvimento, as pulsões de autoconservação do Eu acabam por conseguir que o princípio de prazer seja substituído pelo princípio de realidade. Entretanto, o princípio de realidade não abandona o propósito de obtenção final de prazer, mas exige e consegue impor ao prazer um longo desvio que implica a postergação de uma satisfação imediata, bem como a renúncia às diversas possibilidades de conseguila, e a tolerância provisória ao desprazer [cf. Freud, S. Além do princípio de prazer. In: Hanns, L. A.; Dornbusch, C. et alii (org. e trad.). Obras psicológicas vol. 2. Escritos sobre a Psicologia do Inconsciente. Rio de Janeiro: Imago, 2006, p. 137]. 
na composição de uma vida mortal e heróica, ${ }^{30}$ tal como se depreende da parte final (ainda não citada) da resposta de Ulisses a Calipso:

E se algum deus me ferir no mar cor de vinho, agüentarei:

pois tenho no peito um coração que agüenta a dor.

Já anteriormente muito sofri e muito agüentei

no mar e na guerra: que mais esta dor se junte às outras.

(Od. V, 221-224, trad. F. L.) $)^{31}$

Mas, após o juramento e esta última tentativa por Calipso de persuadir Ulisses, prevendo-lhe desgraças, prometendo-lhe a imortalidade e declarando-se ciumentamente superior em corpo e beleza à Penélope (ao que Ulisses firmemente responde, reafirmando seu desejo do retorno, e, portanto, ainda que implicitamente, sua opção por uma mulher mortal e amada), o herói, já seguro de sua partida, parece voltar uma última vez a partilhar do prazer sexual com a ninfa, tal como o indica direta e explicitamente o modo como é narrada a noite que inicia a despedida entre os dois (como se, assim, demasiado humanamente pudesse ter sido reaquecido o seu desejo pela ninfa):

Foram ambos para o recesso interior da côncava gruta, onde gozaram com o amor, ficando junto um do outro.

(Od. V, 226-227, trad. F. L. modificada)

\footnotetext{
${ }^{30}$ A conexão deste tipo de vida ativa com a opção por um casamento monogâmico em que os cônjuges se respeitam e complementam de um modo que também é familiar e socialmente produtivo é sugerida por Michael N. Nagler em "Dread Goddess revisited": Odysseus' return from the world of pleasure to the world of work, constantly marked in the vocabulary of the poem as a process of trial (peira) and struggle, and in mythology as a progressive return to the protection of Athena, on a practical level means (...) a return from the state in which one sees woman as an object (...) to that in which one can respect her as a partner in the great enterprise of nurturing life (cf. Nagler, op. cit., p. 161).

${ }^{31}$ A versão irônica e mordaz de Eça de Queiróz, em "A perfeição", parece explicitar (na segunda resposta de Ulisses a Calipso) esta elementar dimensão do mundo humano: Porque, na verdade, ó deusa muito ilustre, o meu coração já não suporta esta paz, esta doçura e esta beleza imortal. (...) Considera, ó deusa, que na tua ilha nunca encontrei um charco; um tronco apodrecido; a carcaça de um bicho morto e coberto de moscas zumbidoras. Ó deusa, há oito anos, oito anos terriveis, estou privado de ver o trabalho, o esforço, a luta e o sofrimento... Ando esfaimado por encontrar um corpo arquejando sob um fardo; dois bois fumegantes puxando um arado; homens que se injuriem na passagem de uma ponte; os braços suplicantes de uma mãe que chora; um coxo, sobre a sua muleta, mendigando à porta das vilas... Deusa, há oito anos que não olho para uma sepultura... Não posso mais com esta serenidade sublime! (de Queiróz, op. cit., p. 69-72).
} 
Mas como ainda são necessários quatro dias para que Ulisses construa sua jangada (ou pequena nau de madeira), talvez pudéssemos imaginar com alguma verossimilhança (mesmo sem a explicitação do discreto narrador) que Ulisses - como sugere argutamente E. Delebecque - teria passado as quatro últimas noites na ilha de Ogígia gozando o prazer do amor com Calipso. ${ }^{32}$

Aqui, portanto, mesmo que de uma maneira discreta (que parece indicar algum pudor quanto à imprudente afirmação do triunfo amoroso fora do eixo básico da relação com Penélope), é o primeiro narrador quem (na qualidade de instância máxima de verdade dentro da ficção maior que é a Odisseia) relata não só a derradeira noite (ou noites) de amor entre Ulisses e Calipso, mas também o fato de que durante uma primeira fase da relação entre os dois (mesmo que sua duração não tenha sido bem determinada) Ulisses tenha gozado o prazer de relações sexuais com ela.

A ausência dos companheiros parece, neste caso, justificar a impossibilidade de um foco no banquete (ou no prazer da comida e bebida compartilhada), criando uma situação extremamente propícia ao desenvolvimento de uma intimidade entre os dois, mas aí, também, a discrição do narrador (que parece em inteiro acordo com a intriga central do amor por Penélope) em momento algum sinaliza abertamente algum mal-estar moral de Ulisses por ter sido durante algum tempo o amante de uma deusa-ninfa. Assim (em um contraste negativo com o padrão moral burguês do romance realista do século XIX) seria possível dizer que, embora a infidelidade de Ulisses seja de algum modo velada (em uma curiosa homologia entre a sóbria discrição do protagonistanarrador e a do primeiro narrador da Odisseia), ela jamais implica em Ulisses qualquer traço de arrependimento ou culpabilidade, ${ }^{33}$ tornando possível sua incorporação amena ao padrão dominante do amor pela mulher com quem ele se casou, de quem sente a falta e que agora precisa reconquistar (constituindo o alvo do foco narrativo da segunda metade do poema).

\footnotetext{
${ }^{32}$ Após haver citado os versos 226-227 do canto V da Odisseia, E. Delebecque comenta não sem alguma malícia: Ce n'est pas leur dernière nuit puisqu'il faut encore quatre jours pour construire le navire nécessaire au départ. Quatre jours signifient quatre nuits encore, au terme desquelles Calypso baigne Ulysse et le revêt d'habits à la douce senteur. N'est-ce pas suggérer que ces quatre nuits suprêmes avant la séparation furent des nuits d'amour? (cf. Delebecque, op. cit., p. 106).

${ }^{33}$ A formulação mais precisa (e menos anacrônica por seus pressupostos modernos) desta questão na Odisseia, levando-me à contextualização de conjunto da conclusão, teve como ponto de partida uma pertinente observação crítica do meu colega Antônio Orlando O. Dourado Lopes, a quem com gratidão agradeço aqui.
} 


\section{Conclusão}

A Odisseia, no entanto, não é propriamente um romance realista (sobretudo no bloco narrativo, em primeira pessoa, das viagens maravilhosas de Ulisses), assim como não são propriamente mulheres (ainda que

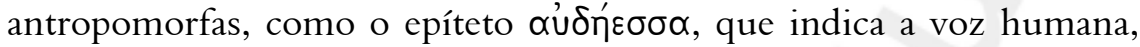
bem o marca) as deusas-ninfas com quem Ulisses mantém (ou simplesmente tem) relações sexuais, e das quais de algum modo depende - em um mundo desconhecido e ameaçador - para poder seguir viagem e retornar à sua terra. ${ }^{34} \mathrm{Se}$, no caso de Circe, a única relação sexual explicitada é aconselhada (ou ordenada) pelo deus Hermes como o único meio efetivo de conseguir que ela retransforme seus companheiros-porcos em homens (e se torne uma anfitriã benfazeja e instrutora), no caso de Calipso, em cuja ilha ele dependerá ao menos de suas instruções e ferramentas para construir sua jangada, a maior intimidade e duração da relação entre os dois (com o conseqüente desejo da ninfa de se tornar sua esposa) parece resultar em um impasse insolúvel, próprio à relação entre dois seres de estatutos ontológicos diferentes (uma deusa e um mortal), o que a abertura do próprio canto $\mathrm{V}$ (1-2) parece bem anunciar, ao evocar alusivamente (na única e genérica ocorrência homérica desta estória) o amor desastrado de Aurora por Titono (cf. Hino homérico a Afrodite 218-238 e Mimnermo 5W), anúncio que é confirmado pelos exemplos também trágicos, evocados por Calipso, do mortal Oríon amado pela deusa Aurora, e do mortal Iásion amado por Deméter (cf. Od. V, 121-127).

Se a volta para a sua terra representa para Ulisses um movimento integrado de retorno à posição de esposo, pai e senhor do palácio (e rei de Ítaca), ou seja: às suas relações no mundo humano, movimento bem caracterizado por W. B. Stanford (em The Ulysses Theme) como "essencialmente para dentro, para casa, e para a normalidade", ${ }^{35}$ poderíamos

\footnotetext{
${ }^{34}$ Para uma relativização análoga mas distinta, ver W. B. Stanford (op. cit., 1992, p. 51): The reason why Homer, Penelope, and the moralists of the later tradition, did not think ill of Odysseus for these infidelities was primarily because in both cases Odysseus was not acting voluntarily. Both Circe and Calypso were demi-goddesses endowed with power to compel their will. Before Odysseus met Circe, Hermes had given him a specific command to grant her request to become her consort. With Calypso there was no direct command from Zeus, but the circumstances were such as to overpower any man of classical antiquity, except perhaps Socrates. Besides, as Penelope would well know in those god-frequented times, to reject the advances of divinities was dangerous indeed. ${ }^{35}$ Cf. Stanford, op cit., 1992, p. 50: The movement of the Odyssey is essentially inwards, homewards, towards normality.
} 
pensar também mais especificamente que a normalidade de uma relação sexual no mundo humano seria a definida por um casamento basicamente monogâmico que resulta na constituição de uma família, implicando, pois, a partir de relações sexuais, a geração de filhos e a conseqüente maternidade e paternidade. ${ }^{36} \mathrm{O}$ movimento do retorno de Ulisses poderia, assim, ser figurado também (nos termos de Michael N. Nagler) como se em direção a "um controle da energia sexual", ou seja: à sua utilização "em formas sancionadas e inerentemente produtivas", o que no poema significa um retorno à lealdade estrita representada por Penélope. ${ }^{37}$ Em oposição a isso (e como se indicando a inconsistência de uma relação ocasional regulada apenas pelo prazer sexual), na versão da Odisseia nenhum filho é gerado a partir das relações sexuais entre Ulisses e Circe ou Calipso, o que poderia inclusive corresponder melhor à verossimilhança, tal como o atesta uma outra versão conhecida, em que, das relações com Ulisses, Circe irá gerar três filhos: Ágrio, Latino e Telégono, e Calipso, dois: Nausítoo e Nausínoo (cf. Teogonia de Hesíodo, v. 1011-1018).

Se, no entanto, desconsiderássemos a natureza divina de Circe e Calipso, e as pensássemos como meras mulheres, poderíamos sem dificuldade nos figurar uma certa (e injusta comparativamente à mulher) liberdade sexual para o homem na Odisseia, o que seria também comprovado (ao menos enquanto possibilidade ou direito) pela estória de Euricléia, que serve, porém, simultaneamente como a indicação de um padrão mais refinado de moralidade no casamento monogâmico

\footnotetext{
${ }^{36}$ Michael N. Nagler, em "Dread Goddess revisited" (op. cit., p. 158), conecta semelhantemente estes domínios a partir do simbolismo do leito de Ulisses e Penélope construído sobre o tronco de uma oliveira (viva): On this level the still-living tree symbolizing the vitality of their relationship conveys a sense quite familiar in myth and literature that marriage involves a creative harnessing of vital, and particularly sexual, energy. John Finley has simply but well said that in the Odyssey 'monogamy is central to the theme of home.' (...) Thus the secret of the bed which only Penelope and Odysseus know is also a sign born in traditional poetic symbolism for their joint identity as generators of social order. (...) The most evident and basic step toward creation of social order is of course the begetting of legitimate children, or what Vernant calls in his happy expression the couple's ability 'to engender a line of descent firmly rooted in the earth'. ${ }^{37}$ Cf. Nagler, op. cit., p. 158: His return from 'moving' to 'stable' and from being outside in 'raw' nature to operating a social institution (on natural power) depends on his ability to control sexual energy. This too was set up through symbolic structures in the exotic world (...); naturally, as the Siren episode establishes, his way is not to avoid temptation (...), but to overcome it. 'Heroic' success is defined as reaching the right context and using vital energy in sanctioned and inherently productive ways, which on the human level of the poem means returning to the loyalty that Penelope had symbolized all along.
} 
estrito em que a fidelidade é recíproca ("A ela, jovem ainda, comprara em tempos Laertes,/ pagando com seus bens o preço de vinte bois;/ e honroua em sua casa, tal como a fiel esposa honrou,/ e nunca com Euricléia se deitou, temendo a ira da mulher”. - Od. I, 430-433). O caso mais óbvio, na Odisseia, de uma presumível liberdade sexual para o homem (desta vez efetivada), o de Agamêmnon trazendo Cassandra de Troia, resulta, porém, em uma desgraça (o assassinato deste casal) da qual faz parte também a contrapartida da infidelidade de Clitemnestra que desde algum tempo vive com Egisto (que também serão punidos com a morte); enquanto, no caso de Helena, a infidelidade para com o marido não apenas é causa da guerra de Troia, mas continua gerando alguma tensão entre o casal (tal como as duas versões opostas sobre as relações entre ela e Ulisses durante a guerra de Troia, a sua primeiro e depois a de Menelau, parecem bem indicar), não sendo, portanto, nenhum destes dois casos (que instauram respectivamente dois planos evidentes de oposição: o de Ulisses para com Agamêmnon e Menelau, e o de Penélope para com Clitemnestra e Helena) bons exemplos odisseicos de uma possível e amoral felicidade nas relações sexuais extra-conjugais. ${ }^{38}$

\section{Referências bibliográficas}

ALLEN, T. W. (ed.). Homeri Opera tomi III et IV. Oxford: University Press, 1987. AMEIS, K. F.; HENTZE, C. (Ed.). Homers Odyssee, Erster Band. Erstes Heft. Leipzig: Teubner, 1920.

AMEIS, K. F.; HENTZE, C. (Ed.). Homers Odyssee, Erster Band.Zweites Heft. Leipzig: Teubner, 1908.

ANDERSON, W. S. Calypso and Elysium. In: TAYLOR Jr., C. H. (org.). Essays on the "Odyssey". Bloomington: Indiana University Press, 1963, p. 73-86.

\footnotetext{
${ }^{38}$ Cf., por exemplo, W. B. Stanford (op. cit., 1992, p. 45-46): Concubinage, even open concubinage, was permitted to husbands but not to wives. Yet here, too, Homer may have introduced a refinement. He implies that happily married men avoided the practice. During the Trojan campaign Menelaus and Odysseus had no concubines, in contrast with the unhappy Agamemnon and Achilles. But Homer makes it clear that husbands might have other motives for avoiding concubinage. (...) Laertes's motive for abstinence was fear. Menelaus's was his lasting infatuation for Helen. Odysseus's was, most likely, affection mixed with prudence. Without his being either afraid of Penelope or infatuated with her, his affection for her merged in his desire to preserve the unity of his home, and his faithfulness was doubly secure.
} 
BUFFIÈRE, F. 3ème partie, chap. VIII, V. Les luttes du sage contre le plaisir et les vices. In: 1956, p. 377-380. . Les mythes d'Homère et la pensée grecque. Paris: Les Belles Lettres,

DELEBECQUE, E. Construction de l'“Odyssée”. Paris: Les Belles Lettres, 1980.

DINDORF, W. (ed.). Scholia graca in Homeri Odysseam tomus II. Oxonii: E Typographeo Academico, 1855.

FREUD, S. Além do princípio de prazer. In: HANNS, L. A.; DORNBUSCH, C. et alii (org. e trad.). Obras psicológicas vol. 2. Escritos sobre a Psicologia do Inconsciente. Rio de Janeiro: Imago, 2006, p. 135-182.

GERMAIN, G. Genèse de l'Odyssée. Paris: Presses Universitaires de France, 1954.

HAINSWORTH, J. B. Books V-VIII. In: HEUBECK, A.; WEST, S.; HAINSWORTH, J. B. A Commentary on Homer's “Odyssey” vol I, Books i-viii. Oxford: University Press, 1990, p. 247-385.

HEUBECK, A. Books IX-XII. In: HEUBECK, A.; HOEKSTRA, A. A Commentary on Homer's “Odyssey” vol. II, Books ix-xvi. Oxford: University Press, 1990, p. 1-143.

HOMERO. Odisseia. Trad. Frederico Lourenço. Lisboa: Cotovia, 2003.

HORACE. Euvres complètes II. Satires; Épitres; Art Poétique. Trad. F. Richard. Paris: Garnier, 1950.

LOUDEN, B. The “Odyssey”. Structure, narration, and meaning. Baltimore: The Johns Hopkins University Press, 1999.

NAGLER, M. N. Dread Goddess revisited. In: SHEIN, S. (Org.). Reading the “Odyssey”. Selected interpretive essays. Princeton: University Press, 1996, p. 141-161.

de QUEIRÓZ, Eça. A perfeição. Lisboa: Marginália, 1995.

REINHARDT, K. Die Abenteuer der “Odyssee”. In: . Tradition und Geist. Göttingen: Vandenhoeck \& Ruprecht, 1960, p. 47-124.

REINHARDT, K. The Adventures in the "Odyssey". In: SHEIN, S. (org.). Reading the "Odyssey". Selected interpretive essays. Princeton: University Press, 1996, p. 63-132.

SEGAL, C. Circean Temptations: Homer, Vergil, Ovid. Transactions of the American Philological Association. Baltimore, vol. XCIX, p. 419-442, 1968.

STANFORD, W. B. (Ed.). The “Odyssey” of Homer vol. I. New York: Macmillan, 1987.

STANFORD, W. B. The Ulysses theme. A study in the adaptability of a traditional hero. Dallas: Spring Publications, 1992.

VERNANT, J.-P. Figures féminines de la mort. In: .Lindividu, la mort, l'amour. Paris: Gallimard, 1989, p. 131-152.

VERNANT, J.-P. The refusal of Odysseus. In: SHEIN, S. (Org.). Reading the “Odyssey”. Selected interpretive essays. Princeton: University Press, 1996, p. 185-189.

VON DER MÜHLL, P. (ed.). Homeri Odyssea. Leipzig: Teubner, 1993. 